\title{
Friends and family matter Most: a trend analysis of increasing e-cigarette use among Irish teenagers and socio- demographic, personal, peer and familial associations
}

Joan Hanafin, Salome Sunday and Luke Clancy*

\begin{abstract}
Background: E-cigarette ever-use and current-use among teenagers has increased worldwide, including in Ireland. Methods: We use data from two Irish waves $(2015,2019)$ of the European School Survey Project on Alcohol and other Drugs (ESPAD) to investigate gender and teenage e-cigarette use ( $n=3421$ 16-year-olds). Using chi-square analyses, we report changes in e-cigarette ever-use, current-use, and associated variables. Using multivariable logistic regression, we analyse the increase in e-cigarette use and socio-demographic, personal, peer and familial associations, focusing on gender differences.

Results: E-cigarette ever-use increased from 23\% in 2015 to 37\% in 2019, and current-use from 10 to 18\%. Compared with 2015, the odds in 2019, of becoming both an e-cigarette ever-user and current-user, were significantly higher for girls than boys (ever-use: AOR 2.67 vs 2.04; current-use: AOR 3.11 vs 1.96). Smoking and e-cigarette use are linked but never-smokers who try e-cigarettes rose significantly from 33 to $67 \%$ and those using e-cigarettes to quit smoking decreased significantly from 17 to 3\%. Almost two-thirds of respondents (66\%) in 2019 said that their reason for trying e-cigarettes was "out of curiosity". Peer smoking is significantly associated with likelihood of e-cigarette ever-use (AOR 6.52) and current-use (AOR 5.45). If "Most/All friends smoke", odds were significantly higher for boys than for girls (everuse AOR 7.07 vs 6.23; current-use AOR 5.90 vs 5.31). Less parental monitoring is significantly associated with greater $e^{-}$ cigarette ever-use (AOR 3.96) and current-use (4.48), and having parents who usually don't know where their child is on Saturday nights was also associated with significantly higher odds for boys than for girls (ever-use AOR 5.42 vs 3.33; current-use AOR 5.50 vs 3.50).

Conclusion: Respondents had significantly higher odds of being e-cigarette ever- and current-users in 2019 compared with 2015. Use is higher among boys but girls are increasingly at risk. Two-thirds had never smoked cigarettes at first ecigarette use; two-thirds used out of curiosity but few (3\%) for smoking cessation. The most prominent risk factors for e-cigarette use were peer- and parent-related, especially so for boys. Interventions that take account of friend and family influences may provide mechanisms for preventing an increasing risk of nicotine addiction.
\end{abstract}

Keywords: E-cigarettes, Teenagers, Gender, Peer smoking, Parental monitoring, ESPAD, Ireland

\footnotetext{
* Correspondence: Iclancy@tri.ie
}

TobaccoFree Research Institute Ireland (TFRI), FOCAS Institute, TU Dublin,

Dublin, Ireland

\section{$\triangle B M C$}

C C The Author(s). 2021 Open Access This article is licensed under a Creative Commons Attribution 4.0 International License, which permits use, sharing, adaptation, distribution and reproduction in any medium or format, as long as you give appropriate credit to the original author(s) and the source, provide a link to the Creative Commons licence, and indicate if changes were made. The images or other third party material in this article are included in the article's Creative Commons licence, unless indicated otherwise in a credit line to the material. If material is not included in the article's Creative Commons licence and your intended use is not permitted by statutory regulation or exceeds the permitted use, you will need to obtain permission directly from the copyright holder. To view a copy of this licence, visit http://creativecommons.org/licenses/by/4.0/ The Creative Commons Public Domain Dedication waiver (http://creativecommons.org/publicdomain/zero/1.0/) applies to the data made available in this article, unless otherwise stated in a credit line to the data. 


\section{Background}

E-cigarette use is increasing worldwide, and e-cigarettes are the most commonly used tobacco product among adolescents [1], including in Ireland [2]. A secondary analysis of five Irish health datasets (all stratified random samples in school-based settings) which included data on teenage tobacco use found that e-cigarette use has risen rapidly among adolescents in Ireland in recent years (from 23\% ever-use in 2014 to $37 \%$ in 2019, and from $3 \%$ current-use in 2014 to $18 \%$ in 2019) [3].

Concerns about e-cigarettes at the level of public health and tobacco control have been aired for some time [4], including the effects of the mainstream tobacco industry's entry into the e-cigarette marketplace. Smokefree legislation, at work and in recreational venues, has denormalised public cigarette smoking but the presence of e-cigarette aerosols in public view may tend to undo this situation [4-6].. Currently, concerns about e-cigarette harms include negative impact on cardiovascular health [7] and potential hazards such as obstructive lung disease from flavorants in e-cigarettes [8]. Passive exposure to second hand aerosol (SHA) from e-cigarettes is also a cause for concern, especially among those with respiratory diseases such as COPD [9, 10], and symptoms of sensory irritation, and general complaints have been reported by non-smokers [11].

Among adolescents, additional and specific potential negative consequences of e-cigarette use have been identified $[12,13]$. There is "compelling" evidence that nicotine exposure during adolescence causes both long-term structural and functional changes in the brain with multiple adverse health consequences [14]. The series of risks identified from nicotine exposure include altered development of cerebral cortex and hippocampus in the developing adolescent brain [12]. The link between teenage e-cigarette use and increased smoking is widely accepted and supported by several reviews [15-17] but the possible mechanisms need to be explored further.

The upward trend in teenage e-cigarette use in Ireland has occurred against the historical backdrop of a twodecade downward trend in teenage cigarette smoking, down from $41 \%$ in 1995 to $14 \%$ in 2015 [18]. Between 2015 and 2019, at the same time that e-cigarette use was increasing rapidly, the downward trend in teenage current cigarette use came to a standstill, remaining at 14\% overall in 2019 and, in fact, reversed for boys, among whom smoking prevalence rose significantly to $16 \%$ in 2019 [2]. The decline of ever cigarette smoking in Ireland seems to continue, albeit not at the level of statistical significance. Elsewhere, it has been suggested that e-cigarette users do not fit the traditional risk profile of cigarette smokers [19], pointing to a separate need to understand e-cigarette use.
Teenage e-cigarette users are more likely to be male gender, older, have higher amounts of pocket money, and report tobacco smoking-related characteristics (including regular and heavier smoking, and having peers who smoke) [20]. Gender differences in teenage smoking have been widely researched (e.g. [21]), but gender differences in teenage e-cigarette use are "relatively unknown" [1]. A recent review of literature on US adolescent e-cigarette use concluded that boys appear to have greater e-cigarette use, but "girls may be at increased risk if e-cigarettes are targeted to them, as it has been for cigarettes" [1]. The Irish data with its clear upward trend point to much higher levels of e-cigarette use among boys than among girls, but little is known about why this is so.

We examine socio-demographic, personal, peer and familial factors previously identified as being associated with e-cigarette use and having comparable data points in our two ESPAD waves. These factors include gender, cigarette smoking, truancy, peer smoking, household composition, parental monitoring, perceived family wealth, and maternal relationship., [2, 15-17, 22, 23].

\section{Methods}

Data are drawn from two Irish waves (2015 and 2019) of the European School Survey Project on Alcohol and other Drugs (ESPAD) [2, 18], a cross-sectional survey carried out every 4 years that collects comparable data in about 35 European countries on substance use, including e-cigarette use.

All methods were carried out in accordance with relevant guidelines and regulations.

\section{Sample}

In Ireland, in both the 2015 and 2019 waves of the ESPAD surveys, students were surveyed using a twostage probability sampling technique: first at national level (a stratified random sample) and then at school level (systematic random sampling of classes). In the first stage at national level, a stratified random sampling of schools in Ireland was carried out. The schools were stratified according to geographic region and school type (secondary, vocational, community/comprehensive), religious affiliation (Roman Catholic, Church of Ireland, inter-denominational), gender (all-boys, all-girls, mixed), and school-level disadvantage status (Delivering Equality of Opportunity in Schools: DEIS vs. non-DEIS).

In the second phase, within schools in the sample, a systematic random sampling technique was used to identify the target sample of those born in 1999 (for the 2015 wave) and 2003 (for the 2019 wave), to produce a nationally representative sample of students who turned 16 years old during the year of data collection, as per ESPAD criteria. Only students present on the day of the 
survey were sampled, yielding a response rate of $86 \%$ for the 2015 sample and $80 \%$ for the 2019 sample. The total valid sample for this study was 3421 16-year-olds, comprising 1472 students (born in 1999) in the 2015 sample, and 1949 students (born in 2003) in the 2019 sample. Completed survey data were entered manually into SPSS v22 as they appeared in the survey. Full accounts of the sampling and data cleaning procedure have been reported elsewhere [2, 22]. All anonymised data are retained on a secure server and accessible through request to the corresponding author.

\section{Variables}

The outcome variables were ever-use and current-use of e-cigarettes.

The independent/exposure variables were sociodemographic, personal, peer, and familial characteristics, measured as described below.

\section{Measurement}

A full list of the questions, and answer categories, from which variables were drawn is in Additional files 1 \& 2 (ESPAD questionnaires 2015 and 2019).

\section{Ever-use and current-use of e-cigarettes}

Two variables measured prevalence, e-cigarette ever-use and e-cigarette current-use.

E-cigarette ever-use was assessed by the question 'Have you ever used e-cigarettes?': Response options were: 'Yes, more than 12 months ago; Yes, in the last 12 months; Yes, in the last 30 days; Never', recoded 'everuse' -no vs yes).

E-cigarette current-use was assessed by the question 'How often have you smoked e-cigarettes during the last 30 days?': 'Not at all; Less than once per week; At least once a week; Almost every day'; recoded 'current-use' -no vs yes.

Socio-demographic variablesincludedgender (male, female), perceived wealth (recoded much better off, better off, about the same, less well off) and household composition (one-parent, two-parent, blended).

\section{Personal, peer, and familial variables}

Students were asked about:

Their cigarette use (2 measures: ever-smoked and current smoking).

Ever-smoked: 'On how many occasions in your lifetime have you smoked cigarettes (excluding ecigarettes)?'; Response options were: 'Number of occasions: $1-2,3-5,6-9,10-19,20-39,40$ or more', recoded 'ever-smoked' -no vs yes.

Current smoking: 'How often have you smoked cigarettes (excluding e-cigarettes) during the last 30 days?'; 'Not at all; less than 1 cigarette per week; less than 1 cigarette per day; $1-5$ cigarettes per day; $6-10$ cigarettes per day; 11-20 cigarettes per day; more than 20 cigarettes per day', recoded 'current smoking' -no vs yes.

\section{Truancy}

Respondents reported the number of days they had skipped or "cut" school in the previous 30 days (recoded none, $1-4$ days, $5+$ days).

\section{Peer smoking}

Respondents reported how many of their friends smoke cigarettes, ('none', 'a few', 'some', 'most' and 'all'; recoded none, a few/some, most/all).

\section{Parental monitoring}

Respondents reported whether their parents (mother or father) know where they spend their Saturday nights ('know always', 'know quite often', 'know sometimes', 'usually don't know').

\section{Relationship with mother}

Respondents reported their satisfaction with their relationship with their mother (recoded as satisfied, neither nor, not satisfied).

We also show sample characteristics for two additional variables (Reasons for trying e-cigarettes: To quit smoking; because friends were using it; out of curiosity) and Relationship with tobacco when first tried an e-cigarette: Never smoked tobacco; smoked occasionally; smoked regularly) but these were not included in the multiple regression analysis because the questions' answer structure was not comparable across both waves.

\section{Statistical analysis}

First, Pearson's chi-square test was used to compare the demographic, personal, peer and familial variables between 2015 and 2019 and to determine whether differences in the variables between the two waves were statistically significant (Table 1). Then, e-cigarette everuse and current-use were examined using a multivariable logistic regression model with e-cigarette ever-use (Table 2) and current-use (Table 3) as the dependent variable, analysed for all and by gender. To assess potential multicollinearity, all variables in the study were adjusted by the dependent variable (e-cigarette ever- and current-use) using Spearman's correlation coefficient and variance inflation factor (VIF) as appropriate between variables, and a VIF $<5$ was used to detect multicollinearity. All analyses and results are presented as adjusted odds ratios (AOR) and 95\% confidence intervals. A $p$-value of .05 was used as a cut-off for significance. All statistical analyses were conducted using STATA version 16 . 


\section{Results}

Changes in prevalence of e-cigarette use between 2015 and 2019

Prevalence of e-cigarette ever-use and current-use among Irish 16-year-olds rose significantly between 2015 and 2019. Prevalence of both is significantly higher for boys than for girls in both waves (Fig. 1). The overall prevalence of ever-use of e-cigarettes increased from 23 to $37 \%$, with boys increasing from 26 to $43.2 \%$ and girls from 19.9 to $31.6 \%$. Current-use increased overall from 10.1 to $18.1 \%$, from 11.6 to $22.9 \%$ in boys and from $8.6 \%$ to 13.6 in girls. Most of the other factors included in our model are statistically unchanged between 2015 and 2019 (Table 1).

\section{Sample differences between 2015 and 2019}

Pearson's chi-square analyses (Table 1) of risk factors associated with e-cigarette use (socio-demographic, personal, peer and familial characteristics) show very few statistically significant differences $(p<.05)$ between the 2015 and 2019 ESPAD waves.

Notable findings concern the relationship with tobacco use when first using e-cigarettes and reasons reported for trying e-cigarettes. In 2015, 33.3\% had never used tobacco when they first used e-cigarettes and this rose to $66.7 \%$ in 2019 . Also, the number who said that they were regular tobacco users when they first used an e-cigarette decreased from 14.9 to $9 \%$ between waves.

Reasons for trying e-cigarettes also changed, with significantly fewer reporting trying e-cigarettes in order to quit smoking in 2019 (3.4\%) than in 2015 (17.3\%). Trying e-cigarettes out of curiosity increased from $63.1 \%$ in 2015 to $66.3 \%$ in 2019, and those who used it because of friends increased from $21.4 \%$ in 2015 to $28.8 \%$ in 2019 .

\section{Trends in e-cigarette ever-use}

Table 2 shows the results of the multivariable logistic regression analysis of e-cigarette ever-use in the 2015 and 2019 ESPAD Ireland surveys, reported as adjusted odds ratios (AOR, 95\% CI) for the total sample, and separately for boys and girls.

The odds of ever-using e-cigarettes increased significantly for the whole sample between 2015 and 2019 (AOR 2.29 , 95\% CI:1.89-2.78), and the increase was more pronounced for girls (AOR 2.67, 95\% CI:2.02-3.54) compared with boys (AOR 2.04, 95\% CI:1.55-2.68). Use of combustible tobacco (both ever and current smoking) was associated with increased odds of ever-using e-cigarettes, with ever-smoking having higher odds for girls (AOR 1.56, 95\% CI:1.12-2.18) and current smoking higher odds for boys (AOR 2.60, 95\% CI:1.71-3.93).

Girls who reported that their families were less welloff than other families had increased odds (AOR 1.76, 95\% CI:1.11-2.78) of being ever-users of e-cigarettes.
Boys living in blended families also had increased odds (AOR 1.85, 95\% CI:1.02-3.35).

Peer smoking was strongly associated with e-cigarette ever-use. Those who reported that "most or all" of their friends smoked had increased odds of ever-using ecigarettes (AOR 6.52, 95\% CI:4.66-9.15) and this was more pronounced for boys (AOR 7.07, 95\% CI:4.3311.55) than for girls (AOR 6.23, 95\% CI:3.87-10.02).

Parental monitoring was significantly associated with ever-use for all (AOR 3.96, 95\% CI:2.54-6.18), and was more important for boys (AOR 5.42, 95\% CI:2.72-10.79) compared with girls (AOR 3.33, 95\% CI:1.84-6.03). Truancy and being in a blended family were associated with increased odds for boys but not for girls.

\section{Trend in e-cigarette current-use}

Table 3 shows the results of the multivariable logistic regression analysis of e-cigarette current-use in the 2015 and 2019 ESPAD Ireland surveys, reported as adjusted odds ratios (AOR, 95\% CI) for the total sample, and separately for boys and girls.

The odds of teenagers being e-cigarette current-users increased significantly between 2015 and 2019 (AOR 2.41, 95\% CI:1.85-3.12); the increase was greater for girls (AOR 3.11, 95\% CI:2.10-4.61) compared with boys (AOR 1.96, 95\% CI: 1.37-2.82). Being a current smoker increased the odds of current-use e-cigarette (AOR 1.78, 95\% CI:1.23-2.55), significantly so for boys (AOR 2.13, 95\% CI:1.30-3.51). The more friends young people have who smoke, the greater their odds of e-cigarette currentuse. Those who reported that "most or all" of their friends smoked had greater odds of e-cigarette currentuse (AOR 5.45, 95\% CI:3.65-8.14), and this was more pronounced for boys (AOR 5.90, 95\% CI:3.31-10.52) than for girls (AOR 5.31, 95\% CI:3.01-9.37).

As with ever-use of e-cigarettes, decreased parental monitoring was also associated with increased odds for teenagers' current-use of e-cigarettes. The odds were significantly increased (AOR 4.48, 95\% CI:2.83-7.11) in young people who say that their parents "usually don't know" where they are on a Saturday night (reference group "parents always know"). Odds were higher for boys (AOR 5.50, 95\% CI:2.85-10.61) than for girls (3.50, 95\% CI:1.79-6.84).

\section{Discussion}

Results from our two ESPAD waves comprising 3421 16-year-olds show that e-cigarette ever-use and currentuse increased significantly between 2015 and 2019 in Ireland. There was a significant rise in never-smokers trying e-cigarettes, with an increase from one-third (33\%) to two-thirds $(67 \%)$ of the sample who had never used tobacco when they first tried an e-cigarette. The link between cigarette and e-cigarette use in teenagers is 
Table 1 Sample characteristics - crosstabulations of socio-demographic, personal, familial, and peer variables in 2015 and 2019 Irish ESPAD Survey Data

\begin{tabular}{|c|c|c|c|}
\hline & \multicolumn{3}{|c|}{ ESPAD Year (2015 and 2019) and significance level ${ }^{a}$} \\
\hline & $\begin{array}{l}2015(n=1472) \\
n(\%)\end{array}$ & $\begin{array}{l}2019(n=1949) \\
\mathrm{n}(\%)\end{array}$ & $p$-value \\
\hline \multicolumn{4}{|l|}{ Gender } \\
\hline Male & $752(51.1)$ & $946(48.5)$ & \\
\hline Female & $720(48.9)$ & $1003(51.5)$ & .140 \\
\hline \multicolumn{4}{|l|}{ E-cigarette ever-use } \\
\hline Yes & $325(23.0)$ & $754(39.0)$ & \\
\hline No & $1088(77.0)$ & $1219(62.7)$ & $<.001$ \\
\hline \multicolumn{4}{|l|}{ E-cigarette current-use } \\
\hline Yes & $143(10.1)$ & $351(18.1)$ & \\
\hline No & $1270(89.9)$ & $1592(81.9)$ & $<.001$ \\
\hline \multicolumn{4}{|l|}{ Ever-smoked } \\
\hline Yes & $473(32.3)$ & $614(31.6)$ & \\
\hline No & $992(67.7)$ & $1328(68.4)$ & .678 \\
\hline \multicolumn{4}{|l|}{ Current smoking } \\
\hline Yes & $191(13.0)$ & $281(14.4)$ & \\
\hline No & $1275(87.0)$ & 1664 (85.6) & .235 \\
\hline \multicolumn{4}{|l|}{ Household composition } \\
\hline Single parent & $262(17.8)$ & $371(19.0)$ & \\
\hline Two parents & $1109(75.3)$ & $1490(76.4)$ & \\
\hline Blended families & $101(6.9)$ & $88(4.5)$ & .010 \\
\hline \multicolumn{4}{|l|}{ Parental Monitoring ${ }^{\mathrm{b}}$} \\
\hline Know always & $906(62.7)$ & $1194(63.2)$ & \\
\hline Know quite often & $337(23.3)$ & $455(24.1)$ & \\
\hline Know sometimes & $128(8.9)$ & $166(8.8)$ & \\
\hline Usually don't know & $73(5.1)$ & $74(3.9)$ & .452 \\
\hline \multicolumn{4}{|l|}{ Skipping School } \\
\hline None & $984(80.1)$ & 1309 (79.6) & \\
\hline $1-4$ days & $198(16.1)$ & $286(17.4)$ & \\
\hline 5 days+ & $47(3.8)$ & $50(3.0)$ & .371 \\
\hline \multicolumn{4}{|l|}{ Perceived family wealth } \\
\hline About the same & $696(48.7)$ & $815(43.3)$ & \\
\hline Much better off & $223(15.6)$ & $308(16.4)$ & \\
\hline Better off & $370(25.9)$ & $580(30.8)$ & \\
\hline Less well off & $141(9.9)$ & $179(9.5)$ & .006 \\
\hline \multicolumn{4}{|l|}{ Peers who smoke } \\
\hline None & $478(33.4)$ & $558(29.8)$ & \\
\hline A few/some & $802(56.1)$ & $1125(60.1)$ & \\
\hline Most/all & $150(10.5)$ & $188(10.1)$ & .056 \\
\hline \multicolumn{4}{|c|}{ Relationship with mother } \\
\hline Satisfied & $1251(87.5)$ & $1621(86.4)$ & \\
\hline Neither nor & $74(5.2)$ & $106(5.6)$ & \\
\hline Not satisfied & $105(7.3)$ & $150(8.0)$ & .640 \\
\hline
\end{tabular}


Table 1 Sample characteristics - crosstabulations of socio-demographic, personal, familial, and peer variables in 2015 and 2019 Irish ESPAD Survey Data (Continued)

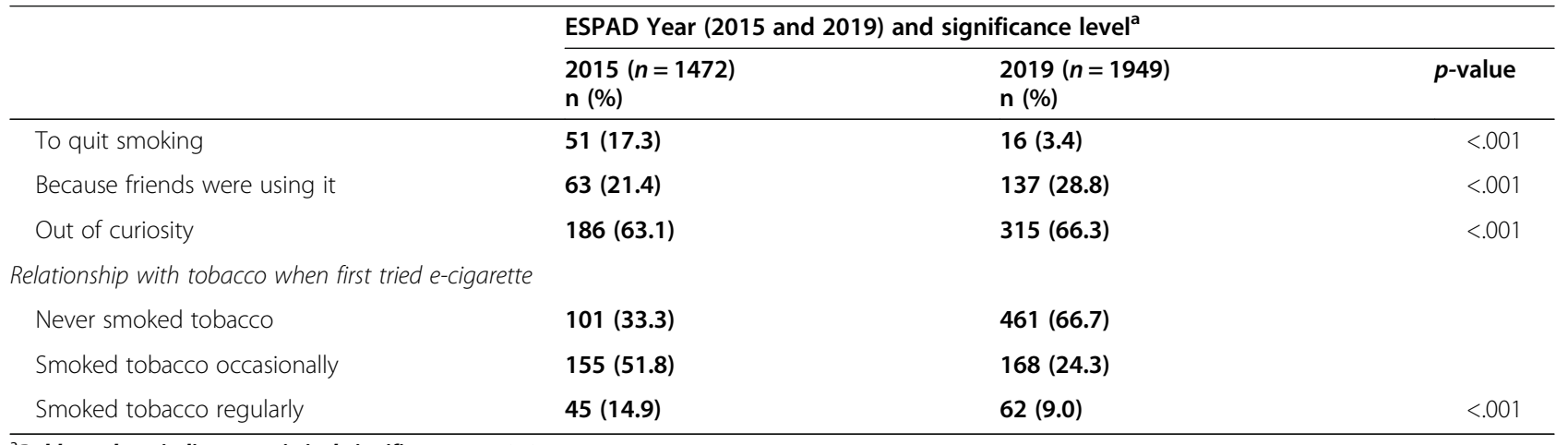

${ }^{a}$ Bold numbers indicate statistical significance at $<0.05$

${ }^{\mathrm{b}}$ Parents know where child is on Saturday nights

clear but the mechanisms are uncertain. The longstanding Gateway Theory [24] of the centrality of nicotine addiction in the progression to other drugs is insufficient to explain fully the progression to cigarettes from ecigarettes, especially as cigarette use often precedes ecigarettes. The Common Liability Theory [25] allows for wider inputs from environmental and genetic influences, while the Catalyst Model [26] helps consider the factors influencing initiation and progression, which could possibly extend to a diversion model preventing progression to smoking [27]. Our finding of a marked increase in ecigarette use in association with peer cigarette smoking allows for the possibility that a catalyst effect occurred but does not exclude the possibility of some "diversion" occurring, perhaps resulting in less progression to smoking in girls [28].

\section{Gender differences in e-cigarette use}

From the outset, boys in our trend analyses were more likely to be both ever- and current-users of e-cigarettes. This is in line with many other studies $[1,20]$. Various theories have been offered to explain gender and substance use including tobacco and e-cigarettes, such as Connell's (2005) influential construct of hegemonic masculinity and how it puts men at risk of harmful health behaviours and consequences that can be destructive for them [29], including for teenage boys [30,31], and Butler's [32] consequential theory of gender performativity that gender is not an essential, biologically determined quality or an inherent identity, but is repeatedly performed, based on, and reinforced by, societal norms, this repeated performance of gender being also performative - applied to smoking by women in Australia by Gilbert and colleagues [33]. They argued that smoking is "a gender act that can be internalised and which, when repeatedly performed by women in gender-appropriate ways, constructs a 'feminine' gender identity" [32, 33]. Such theories and how they relate to our findings on gendered e-cigarette use are outside the scope of our data. We raise them here to acknowledge that our findings have a broader and deeper context within discourses on gender and substance use [31].

Boys have higher prevalence of e-cigarette use but the rate of increase in this study is significantly greater for girls, and this was particularly pronounced for currentuse, with the trend analysis showing girls having more than 50\% higher odds (AOR 3.11, 95\% CI 2.10-4.61) than boys (AOR 1.96, 95\% CI 1.37-2.82) of being $e$ cigarette current-users in 2019 compared with 2015. This gendered pattern of substance use showing initial high male use, with female use subsequently over-taking that of males reflects historical patterns of women's and men's tobacco use, driven, in part at least, by the tobacco industry's gendered marketing, and exploitation of social change and social disruption [34-36], such as the post-war targeting of women by the tobacco industry "as an equality and freedom issue" [36]. The latter comprised advertising and marketing by the industry, specifically and successfully targeted to women and girls, a market identified as a large untapped lucrative reservoir [34-36]. E-cigarette advertising and direct and covert marketing uses strikingly similar techniques to those used previously by the cigarette industry [37] - featuring young, attractive models, sponsorship of sports events and parties, product placement, and direct payments to social media influencers [37]. We add support to Kong et al. (2017) who observed that, while boys in the U.S. appear to have greater use of e-cigarettes, girls may be at increased risk if e-cigarettes are targeted to them "as it has been for cigarettes" and we join in calling for further research on gender differences in e-cigarette use, particularly in gendered rates of increase, and on the role of industry advertising and marketing, including the gendered nature of such activities on the internet [1]. We recommend that insights about gender, from emerging theories and historical developments such as those 
Table 2 Socio-demographic, personal, peer and familial variables associated with e-cigarette ever-use in the 2015 \& 2019 ESPAD Surveys: multivariable logistic regression

\begin{tabular}{|c|c|c|c|}
\hline & \multicolumn{3}{|c|}{ E-cigarette ever-use (Adjusted Odds Ratio (AOR), total sample and by gender) } \\
\hline & Total (AOR, 95\% Cl) & Boys (AOR, 95\% Cl) & Girls (AOR, 95\% Cl) \\
\hline \multicolumn{4}{|l|}{ Gender } \\
\hline Male & 1 & & \\
\hline Female & $0.99(0.83,1.20)$ & N/A & N/A \\
\hline \multicolumn{4}{|l|}{ ESPAD Year } \\
\hline 2015 & 1 & 1 & 1 \\
\hline 2019 & $2.29(1.89,2.78)$ & $2.04(1.55,2.68)$ & $2.67(2.02,3.54)$ \\
\hline \multicolumn{4}{|l|}{ Ever smoked } \\
\hline No & 1 & 1 & 1 \\
\hline Yes & $1.39(1.10,1.75)$ & $1.23(0.89,1.71)$ & $1.56(1.12,2.18)$ \\
\hline \multicolumn{4}{|l|}{ Current smoking } \\
\hline No & 1 & 1 & 1 \\
\hline Yes & $1.76(1.31,2.38)$ & $2.60(1.71,3.93)$ & $1.14(0.73,1.79)$ \\
\hline \multicolumn{4}{|l|}{ Household composition } \\
\hline Single parent & 1 & 1 & 1 \\
\hline Two parents & $0.84(0.66,1.08)$ & $0.91(0.63,1.30)$ & $0.80(0.55,1.15)$ \\
\hline Blended families & $1.43(0.93,2.16)$ & $1.85(1.02,3.35)$ & $1.14(0.61,2.13)$ \\
\hline \multicolumn{4}{|l|}{ Parental Monitoring } \\
\hline Know always & 1 & 1 & 1 \\
\hline Know quite often & $1.99(1.61,2.46)$ & $1.94(1.43,2.62)$ & $2.04(1.51,2.75)$ \\
\hline Know sometimes & $3.12(2.52,4.63)$ & $3.15(2.06,4.83)$ & $3.68(2.35,5.75)$ \\
\hline Usually don't know & $3.96(2.54,6.18)$ & $5.42(2.72,10.79)$ & $3.33(1.84,6.03)$ \\
\hline \multicolumn{4}{|l|}{ Skipping School } \\
\hline None & 1 & 1 & 1 \\
\hline $1-4$ days & $0.86(0.67,1.10)$ & $0.83(0.58,1.18)$ & $0.90(0.64,1.27)$ \\
\hline 5 days + & $1.56(0.95,2.56)$ & $2.17(1.08,4.36)$ & $1.07(0.50,2.30)$ \\
\hline \multicolumn{4}{|l|}{ Perceived wealth } \\
\hline About the same & 1 & 1 & 1 \\
\hline Much better off & $1.11(0.85,1.45)$ & $1.30(0.88,1.91)$ & $0.96(0.66,1.40)$ \\
\hline Better off & $1.01(0.81,1.26)$ & $1.31(0.96,1.79)$ & $0.80(0.59,1.09)$ \\
\hline Less well off & $1.29(0.93,1.78)$ & $0.94(0.59,1.51)$ & $1.76(1.11,2.78)$ \\
\hline \multicolumn{4}{|l|}{ Peers who smoke } \\
\hline None & 1 & 1 & 1 \\
\hline A few/some & $2.74(2.17,3.45)$ & $3.12(2.22,4.38)$ & $2.47(1.79,3.41)$ \\
\hline Most/all & $6.52(4.66,9.15)$ & $7.07(4.33,11.55)$ & $6.23(3.87,10.02)$ \\
\hline \multicolumn{4}{|l|}{ Maternal relationship } \\
\hline Satisfied & 1 & 1 & 1 \\
\hline Neither nor & $1.65(1.13,2.40)$ & $2.22(1.33,3.72)$ & $1.55(0.65,2.04)$ \\
\hline Not satisfied & $1.36(0.98,1.89)$ & $1.36(0.85,2.18)$ & $1.32(0.83,2.10)$ \\
\hline
\end{tabular}

Bold numbers indicate statistical significance at $<.05$

mentioned above, be incorporated into both policymaking and health education programmes that are intended to reduce children's e-cigarette use.
We agree with O'Leary et al. (2019) that, while the state and use of social media are ever changing, the potential to use social media as a form of promotion for 
Table 3 Socio-demographic, personal, peer and familial variables associated with e-cigarette current-use in the 2015 \& 2019 ESPAD Surveys: multivariable logistic regression

\begin{tabular}{|c|c|c|c|}
\hline & \multicolumn{3}{|c|}{ E-cigarette current-use Adjusted Odds Ratio (AOR) (total sample and by gender) } \\
\hline & Total (AOR, 95\% Cl) & Boys (AOR, 95\% Cl) & Girls (AOR, 95\% Cl) \\
\hline \multicolumn{4}{|l|}{ Gender } \\
\hline Male & 1 & & \\
\hline Female & $1.03(0.81,1.30)$ & N/A & N/A \\
\hline \multicolumn{4}{|l|}{ ESPAD Year } \\
\hline 2015 & 1 & 1 & 1 \\
\hline 2019 & $2.41(1.85,3.12)$ & $1.96(1.37,2.82)$ & $3.11(2.10,4.61)$ \\
\hline \multicolumn{4}{|l|}{ Ever smoked } \\
\hline No & 1 & 1 & 1 \\
\hline Yes & $1.14(0.84,1.55)$ & $1.19(0.77,1.82)$ & $1.13(0.72,1.76)$ \\
\hline \multicolumn{4}{|l|}{ Current smoking } \\
\hline No & 1 & 1 & 1 \\
\hline Yes & $1.78(1.23,2.55)$ & $2.13(1.30,3.51)$ & $1.50(0.87,2.59)$ \\
\hline \multicolumn{4}{|l|}{ Household composition } \\
\hline Single parent & 1 & 1 & 1 \\
\hline Two parents & $0.94(0.68,1.29)$ & $1.16(0.72,1.84)$ & $0.75(0.48,1.62)$ \\
\hline Blended families & $1.46(0.89,2.44)$ & $1.53(0.72,3.24)$ & $1.37(0.68,2.76)$ \\
\hline \multicolumn{4}{|l|}{ Parental Monitoring } \\
\hline Know always & 1 & 1 & 1 \\
\hline Know quite often & $2.22(1.69,2.92)$ & $2.62(1.76,3.90)$ & $1.90(1.29,2.81)$ \\
\hline Know sometimes & $3.53(2.49,5.01)$ & $4.06(2.49,6.63)$ & $3.09(1.85,5.15)$ \\
\hline Usually don't know & $4.48(2.83,7.11)$ & $5.50(2.85,10.61)$ & $3.50(1.79,6.84)$ \\
\hline \multicolumn{4}{|l|}{ Skipping School } \\
\hline None & 1 & 1 & 1 \\
\hline $1-4$ days & $0.86(0.63,1.18)$ & $0.68(0.42,1.10)$ & $1.03(0.68,1.58)$ \\
\hline 5 days + & $1.42(0.81,2.51)$ & $1.08(0.49,2.37)$ & $1.70(0.74,3.90)$ \\
\hline \multicolumn{4}{|l|}{ Perceived wealth } \\
\hline About the same & 1 & 1 & 1 \\
\hline Much better off & $1.14(0.82,1.59)$ & $1.04(0.65,1.67)$ & $1.20(0.75,1.93)$ \\
\hline Better off & $0.77(0.57,1.03)$ & $0.81(0.53,1.22)$ & $0.73(0.48,1.11)$ \\
\hline Less well off & $1.28(0.87,1.88)$ & $1.26(0.72,2.20)$ & $1.35(0.79,2.33)$ \\
\hline \multicolumn{4}{|l|}{ Peers who smoke } \\
\hline None & 1 & 1 & 1 \\
\hline A few/some & $2.13(1.54,2.96)$ & $2.23(1.39,3.59)$ & $2.11(1.34,3.33)$ \\
\hline Most/all & $5.45(3.65,8.14)$ & $5.90(3.31,10.52)$ & $5.31(3.01,9.37)$ \\
\hline \multicolumn{4}{|c|}{ Relationship with mother } \\
\hline Satisfied & 1 & 1 & 1 \\
\hline Neither nor & $1.23(0.77,1.97)$ & $1.37(0.68,2.79)$ & $1.25(0.66,2.37)$ \\
\hline Not satisfied & $1.55(1.06,2.26)$ & $1.40(0.79,2.49)$ & $1.64(0.98,2.74)$ \\
\hline
\end{tabular}

Bold numbers indicate statistical significance at $<.05$ 


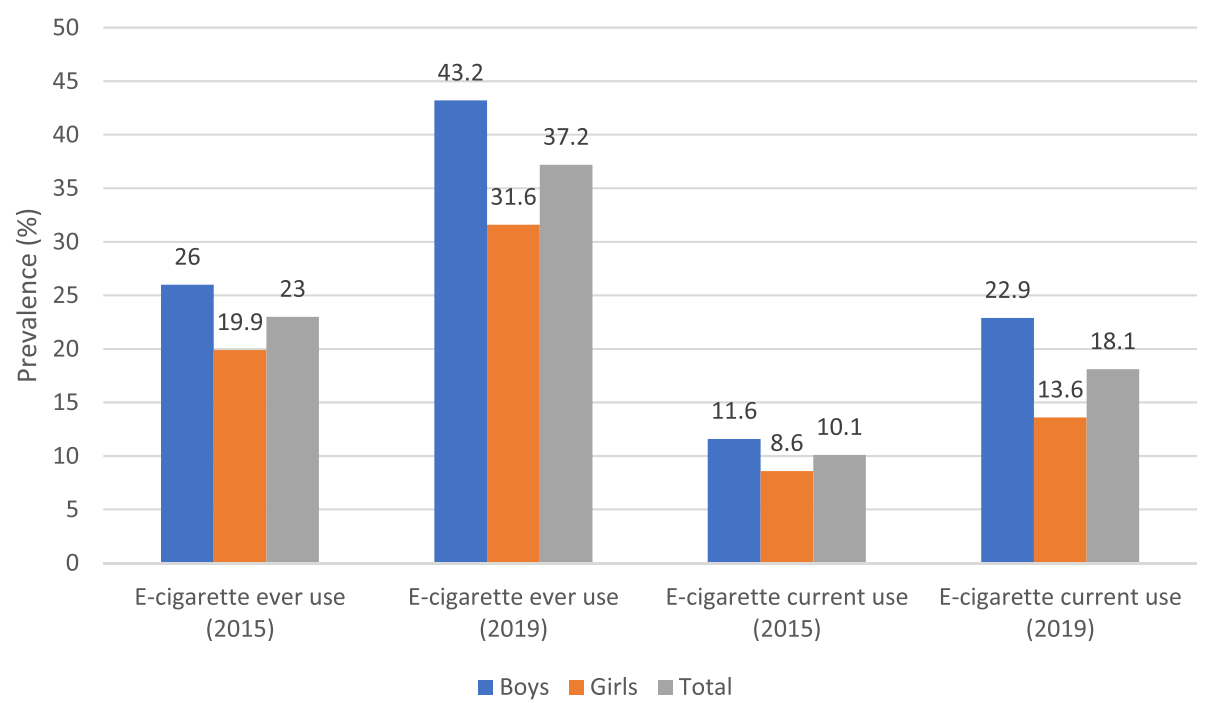

Fig. 1 Changes in \% prevalence of e-cigarette ever-use and current-use between 2015 and 2019 (Boys, Girls, Total). Source: ESPAD Ireland Survey Data 2015 and 2019

healthy behaviours, especially among adolescents, will continue to offer promise [38]. Thus, we extend to the domain of tobacco and e-cigarette use their call for education interventions for teenagers [38].

Also, we draw attention to findings from ourselves and others regarding the potentially different online worlds inhabited by teenage girls (social media platforms) and teenage boys (gaming platforms) that have been identified $[2,39]$. This leads us to speculate, for example, that boys may be targeted through gaming platforms and that girls' rapidly increasing e-cigarette use may be related to their greater social media use. The scope within these parallel gendered domains for targeted marketing of ecigarettes by industry merits further research and we also support calls for regulatory action to prohibit sponsored e-cigarette content on social media platforms used by youth $[40,41]$.

\section{E-cigarette use and smoking}

The link between cigarette smoking and e-cigarette use has been well-established [15-17] and our findings support this, but with gender differences. Girls who had ever-smoked had higher odds (AOR 1.56, 95\% CI: 1.122.18) of ever-using e-cigarettes. Boys who were current smokers had more than twice the odds of being $e$ cigarette ever-users (AOR 2.60, 95\% CI: 1.71-3.93). Thus, differences in experimentation and continuation of both smoking and e-cigarette use appear to be gendered, pointing to different characteristics between the cigarette-smoking and e-cigarette using populations or to gender differences that require further exploration. We lend some support to the findings of Creamer et al. (2021) that, regarding psychosocial risk factors for cigarette smoking, e-cigarette users do not fit the traditional risk profile of cigarette smokers, and also require further research [19].

\section{Peer influence}

Adolescent peer social networks have been found to be important for health behaviour choices, with health behaviour similarity found to be driven by homophilic social selection and/or social influence [42]. Studies of adolescent social networks, including online networks, suggest that friends' online behaviours are a viable source of peer influence [23]. Those with more peers who smoke have much higher odds of being ever-users of e-cigarettes, and this pattern was particularly strong for boys. Peer smoking was similarly implicated in $e$ cigarette current-use and, again, gender differences showed a somewhat stronger influence of peers on boys than on girls in relation to current-use of e-cigarettes. A review of 26 studies examining adolescents' susceptibility to peer pressure to engage in risky behaviours identified two primary trends: one, that adolescent males appear to be more susceptible to peer influences that encourage risk-taking behaviours; and the other, that there are no consistent gender differences [43]. McCoy and colleagues conjecture [43] that, as attitudes about genderappropriate behaviour shift across historical time, it may be that male and female teenage experiences are becoming increasingly similar, for example in experiencing comparable levels of deviant peer pressure around substance use in particular and also that differences across types of risky behaviours may "even out", causing gender differences to disappear. 
Gender being an incomplete explanation of the observed differences in teenage e-cigarette use, we draw attention to intersectionality [44] as a promising framework to achieve new understandings of teenage tobacco use. Although intersectionality has been examined in relation to adult smoking cessation (e.g., [45, 46]), there is little or no research to date on teenage tobacco use (and consequent health inequalities) that captures the complexity of "multiple aspects of identity" [41], employing analyses at the intersections of, for example, categories of gender, race, class/SES, disability, sexuality, and religion. More complex conceptual analyses are needed to generate new insights into this emergent and increasing problem of new tobacco product use by young people.

As our findings provide further support for the many studies that have found that peer smoking influences teenage e-cigarette use [20, 47-50], we suggest that health education interventions that take account of peer influences remain important, particularly as higher levels of peer e-cigarette use $[51,52]$ and favourable ecigarette peer norms [53] have been found by other researchers to be related to higher odds of personal ecigarette use.

\section{Parental monitoring}

Parental monitoring was a separately important factor in explaining teenagers' e-cigarette use and we add further support to our previous ESPAD findings [54, 55] - as well as findings from other studies $[22,56]$ - showing that lack of parental monitoring remains a significant predictor for all illicit substance use in the best-fitting models. However, our finding contrasts with that of Fotiou et al. [49] who reported that low parental monitoring correlates with tobacco but not with e-cigarette use. Our finding about parental monitoring was also gendered, being more significant for teenage boys than for teenage girls.

We highlight an urgent need for health education programmes that address the increasing trend of teenage ecigarette use and recommend that such programmes acknowledge the important influences of friends and families.

\section{Limitations of the study}

We report on comparable nationally representative samples of teenagers from 2015 and 2019, and note significant gender differences. However, the quantitative methodology does not allow for more in-depth understanding of these gender differences nor why they occur. Thus, in the Discussion section, we offer some possible theories that might be tested in future research to explain the now well-established gender differences in ecigarette use. Also, longitudinal and/ or qualitative approaches would provide greater insight into teenage ecigarette use and the associations with the increased risk observed over time.

\section{Conclusion}

Overall, the likelihood of Irish teenagers being ecigarette users increased significantly between 2015 and 2019. Boys are more likely to be both ever- and currentusers of e-cigarettes but our trend analyses show that, from one wave to the next, the risk to girls became greater. This differential in rate of increase may reflect differences in how girls and boys are targeted through advertising, gaming and social media platforms, an area requiring further research.

The majority of teenage e-cigarette users had never smoked cigarettes when they first used e-cigarettes, and very few used e-cigarettes as a smoking cessation aid. Rather, the majority used them out of curiosity and, to a lesser extent, because friends did. Our regression model with socio-demographic, personal, peer and familial associations shows that the most prominent risk factors for e-cigarette use were friend and family influences, especially so for boys. In order to support regulation of this rapidly evolving market of new tobacco products, we highlight the role of parental monitoring and peer smoking influences as potential intervention mechanisms for prevention of this increasing addiction to ecigarettes.

\section{Supplementary Information}

The online version contains supplementary material available at https://doi. org/10.1186/s12889-021-12113-9.

\section{Additional file 1.}

Additional file 2.

\section{Acknowledgements}

We thank the RCDH Trust and the Department of Health Ireland for their financial support We acknowledge our colleagues in EMCDDA (European Monitoring Centre for Drugs and Drug Addiction) and the ESPAD group. We also wish to acknowledge the important part played by colleagues, Sheila Keogan, in the management and supervision of the 2 waves of ESPAD Ireland in 2015 and 2019 and of the data collection and curation by Keishia Taylor, Dr. Kate Babineau, Dr. Ermelinda Furtado da Luz Brzychcyk, and Ellen Whelan.

Consent

Written Consent was obtained from the parents/guardians for the ESPAD surveys.

Information leaflets and consent forms were supplied to each subject.

\section{Authors' contributions}

Joan Hanafin: Conceptualization, Methodology, Writing- Original draft preparation, Reviewing and Editing, Supervision, Visualization Salome Sunday: Formal analysis, Data curation, Statistical examination, Reviewing and Editing Luke Clancy: Conceptualization, Supervision Visualization, Investigation, Reviewing and Editing, Resources, Funding acquisition. The author(s) read and approved the final manuscript. 


\section{Funding}

The research was supported by a grant from.

1.) The Royal City of Dublin hospital trust Grant no. 184and

2.) Dept. of health of Ireland ESPAD tender 2019

\section{Availability of data and materials}

All data are available on reasonable request to the corresponding author: Iclancy@tri.ie

\section{Declarations}

\section{Ethics approval and consent to participate}

Ethics approval was received from Research Ethics and Integrity Committee of TUDublin ref. REC-18-126.

\section{Consent for publication}

Not applicable.

\section{Competing interests}

The authors declare that they have no competing interests, financial or nonfinancial.

Received: 17 June 2021 Accepted: 1 October 2021

Published online: 03 November 2021

\section{References}

1. Kong G, Kuguru KE, Krishnan-Sarin S. Gender differences in U.S. adolescent E-cigarette use. Curr Addiction Rep. 2017;4(4):422-30. https://doi.org/10.1 007/s40429-017-0176-5.

2. Sunday S, Keogan S, Hanafin J, Clancy L. ESPAD 2019 Ireland: results from the European schools project on alcohol and other drugs in Ireland. [internet]. Dublin: TFRl; 2020. Available from: https://drive.google.com/file/ d/1 qyaQwcxQhLbiDQrl2ap6SuNMmHa_NWcy/view

3. Hanafin J, Sunday S, Keogan S, Clancy L. Worrying changes in adolescent ecigarette use 2014-2019: a secondary analysis of five Irish health datasets. Ir J Med Sci. 2021:190:3.3.

4. Glynn TJ. E-cigarettes and the future of tobacco control. CA Cancer J Clin. 2014;64(3):164-8. https://doi.org/10.3322/caac.21226.

5. Hanafin J, Clancy L. A qualitative study of e-cigarette use among young people in Ireland: incentives, disincentives, and putative cessation. PLoS One. 2021;15(12):e0244203. https://doi.org/10.1371/journal.pone.0244203.

6. Clancy L, Babineau K. E-cigarettes: effective cessation tools or public health threat? QJM. 2016;109(2):79-81. https://doi.org/10.1093/qjmed/hcv223.

7. Lippi G, Favaloro EJ, Meschi T, Mattiuzzi C, Borghi L, Cervellin G. E-cigarettes and cardiovascular risk: beyond science and mysticism. Semin Thromb Hemost. 2014;40(1):60-5. https://doi.org/10.1055/s-0033-1363468.

8. Barrington-Trimis JL, Samet JM, McConnell R. Flavorings in electronic cigarettes an unrecognized respiratory health Hazard? JAMA. 2014;312(23): 2493-4. https://doi.org/10.1001/jama.2014.14830.

9. Rosenkilde KL, Bønløkke J, Bendstrup E, Bilde M, Glasius M, Gutzke VH, et al. An RCT of acute health effects in COPD-patients after passive vape exposure from e-cigarettes. Eur Clin Respir J. 2020;8(1):1861580. https://doi. org/10.1080/20018525.2020.1861580.

10. Keogan S, Alonso T, Sunday S, Tigova O, Fernández E, López MJ, et al. Lung function changes in patients with chronic obstructive pulmonary disease (COPD) and asthma exposed to secondhand smoke in outdoor areas. J Asthma. 2021;58(9):1169-75. https://doi.org/10.1080/02770903.2020.1766062.

11. Tzortzi A, Teloniatis S, Matiampa G, Bakelas G, Tzavara C, Vyzikidou VK, et al. Passive exposure of non-smokers to E-cigarette aerosols: sensory irritation, timing and association with volatile organic compounds. Environ Res. 2020; 182:108963. https://doi.org/10.1016/j.envres.2019.108963.

12. England $L$, Bunnell RE, Pechacek TF, Tong VT, McAfee TA. Nicotine and the developing human. Am J Prev Med. 2015;49(2):286-93. https://doi.org/10.1 016/j.amepre.2015.01.015

13. Roditis ML, Halpern-Felsher B. Adolescents' Perceptions of Risks and Benefits of Conventional Cigarettes, E-cigarettes, and Marijuana: A Qualitative Analysis. J Adolesc Health. 2015/06/23 ed. 2015:57(2):179-85.

14. Dwyer JB, Broide RS, Leslie FM. Nicotine and brain development. Birth Defects Res C: Embryo Today. 2008;84(1):30-44. https://doi.org/10.1002/ bdrc.20118
15. Soneji S, Barrington-Trimis JL, Wills TA, Leventhal AM, Unger JB, Gibson LA et al. Association between initial use of e-cigarettes and subsequent cigarette smoking among adolescents and young adults: a systematic review and Meta-analysis. JAMA Pediatr. 2017;171(8):788-97. https://doi. org/10.1001/jamapediatrics.2017.1488.

16. O'Brien D, Long J, Lee C, McCarthy A, Quigley J. Electronic cigarette use and tobacco cigarette smoking initiation in adolescents: an evidence review. 2020; Available from: https://www.hrb.ie/fileadmin/2._Plugin_related_files/ Publications/2020_publication-related_files/2020_HIE/Evidence_Centre/ Electronic_cigarette_use_and_tobacco_cigarette_smoking_initiation_in_a dolescents.pdf

17. Aladeokin A, Haighton C. Is adolescent e-cigarette use associated with smoking in the United Kingdom?: a systematic review with meta-analysis. Tob Prev Cessat. 2019. https://doi.org/10.18332/tpc/108553.

18. Clancy L, Taylor K, Babineau K, Keogan S, Whelan E. ESPAD 2015: European School Survey Project on Alcohol \& Other Drugs in Ireland. [Internet]: TFRI for the Department of Health, Ireland; 2016. Available from: https://www.tri. ie/uploads/5/2/7/3/52736649/espad_2015_ireland_final.pdf.

19. Creamer MR, Dutra LM, Sharapova SR, Gentzke AS, Delucchi KL, Smith RA et al. Effects of e-cigarette use on cigarette smoking among U.S. youth, 2004-2018. Prev Med. 2021;142:106316.

20. Perikleous EP, Steiropoulos P, Paraskakis E, Constantinidis TC, Nena E. ECigarette Use Among Adolescents: An Overview of the Literature and Future Perspectives. Front Public Health [Internet]. 2018;6 [cited 2021 Feb 23]. Available from: https://www.frontiersin.org/articles/10.3389/fpubh.2018. 00086/full.

21. Grard A, Schreuders M, Alves J, Kinnunen JM, Richter M, Federico B, et al. Smoking beliefs across genders, a comparative analysis of seven European countries. BMC Public Health. 2019;19(1):1-12. https://doi.org/10.1186/s12 889-019-7700-6.

22. Szoko N, Ragavan MI, Khetarpal SK, Chu K-H, Culyba AJ. Protective Factors Against Vaping and Other Tobacco Use. Pediatrics. 2021;148(2):1-9.

23. Huang GC, Unger JB, Soto D, Fujimoto K, Pentz MA, Jordan-Marsh M, et al. Peer influences: the impact of online and offline friendship networks on adolescent smoking and alcohol use. J Adolesc Health. 2014;54(5):508-14. https://doi.org/10.1016/j.jadohealth.2013.07.001.

24. Kandel ER, Kandel DB. A molecular basis for nicotine as a gateway drug. N Engl J Med. 2014;371(10):932-43. https://doi.org/10.1056/NEJMsa1405092.

25. Vanyukov MM, Tarter RE, Kirillova GP, Kirisci L, Reynolds MD, Kreek MJ, et al. Common liability to addiction and 'gateway hypothesis': Theoretical, empirical and evolutionary perspective. Drug Alcohol Depend. 2012/01/18 ed. 2012;123(Suppl 1(Suppl 1)):S3-17. https://doi.org/10.1016/j.drugalcdep.2 011.12 .018 .

26. Schneider S, Diehl K. Vaping as a catalyst for smoking? An initial model on the initiation of electronic cigarette use and the transition to tobacco smoking among adolescents. Nicotine Tob Res. 2016;18(5):647-53. https:// doi.org/10.1093/ntr/ntv193.

27. Selya AS, Foxon F. Trends in Electronic Cigarette Use and Conventional Smoking: Quantifying a Possible "Diversion" Effect among US Adolescents. Addiction [Internet]. 2021; Available from: https://doi.org/ 10.1111/add.15385

28. Sunday S, Hanafin J, Clancy L. Increased smoking and e-cigarette use among Irish teenagers: A new threat to Tobacco Free Ireland 2025. ERJ Open Res. 2021;7:00438-2021. https://doi.org/10.1183/23120541.00438-2021.

29. Connell RW. Masculinities. Cambridge: Polity; 1995.

30. O'Beaglaoich C, McCutcheon J, Conway PF, Hanafin J, Morrison TG. Adolescent suicide ideation, depression and self-esteem: relationships to a new measure of gender role conflict. Front Psychol. 2020;11:111. https://doi. org/10.3389/fpsyg.2020.00111.

31. Mac an Ghaill M, Hanafin J, Conway PF. Gender politics and exploring masculinities in Irish education teachers, materials and the media; 2002.

32. Butler J. Gender trouble: feminism and the subversion of identity: Routledge; 2011. 272 p. https://doi.org/10.4324/9780203824979.

33. Gilbert E. Performing femininity: young women's gendered practice of cigarette smoking. J Gend Stud. 2007;16(2):121-37. https://doi.org/10.1080/ 09589230701324579

34. Berridge $V$. Marketing health: smoking and the discourse of public health in Britain, 1945-2000, vol. 19. Oxford: Oxford University Press; 2008.

35. Brandt AM. Cigarette century: the rise, fall and deadly persistence of the product that defined America, vol. 16. New York: Basic Books; 2007. 
36. Hanafin J, Clancy L. History of Tobacco Production and Use. In: Progress in Respiratory Research [Internet]; 2015. p. 1-18. Available from: https://www. karger.com/DOI/10.1159/000369289.

37. Strick K. E-cigarettes: time to realign our approach? Lancet. 2019;394(10206): 1297. https://doi.org/10.1016/S0140-6736(19)32277-9.

38. Leary MP, Clegg EN, Santella ME, Murray PJ, Downs JS, Olfert MD. Consumption of health-related content on social media among adolescent girls: mixed-methods pilot study. JMIR Formative Res. 2019;3(1):e11404. https://doi.org/10.2196/11404.

39. ESPAD Group. ESPAD report 2019: results from the European school survey project on alcohol and other drugs [internet]: EMCDDA Joint Publications, Publications Office of the European Union, Luxembourg; 2020. Available from: http://www.espad.org/sites/espad.org/files/2020.3878_EN_04.pdf

40. Vogel EA, Ramo DE, Rubinstein ML, Delucchi KL, Darrow SM, Costello C, et al. Effects of Social Media on Adolescents' Willingness and Intention to Use E-Cigarettes: An Experimental Investigation. Nicotine Tobacco Res [Internet]. 2020;(ntaa003). [cited 2021 Feb 23] Available from: https://doi.org/ 10.1093/ntr/ntaa003;23(4):694-701.

41. Bowe AK, Doyle F, Stanistreet D, O'Connell E, Durcan M, Major E, et al. Ecigarette-only and dual use among adolescents in Ireland: emerging Behaviours with different risk profiles. Int J Environ Res Public Health. 2021; 18(1):332. https://doi.org/10.3390/ijerph18010332.

42. Montgomery SC, Donnelly M, Bhatnagar P, Carlin A, Kee F, Hunter RF. Peer social network processes and adolescent health behaviors: a systematic review. Prev Med. 2020;130:105900. https://doi.org/10.1016/j.ypmed.2019.1 05900.

43. McCoy SS, Dimler LM, Samuels DV, Natsuaki MN. Adolescent susceptibility to deviant peer pressure: does gender matter? Adolescent Res Rev. 2019; 4(1):59-71. https://doi.org/10.1007/s40894-017-0071-2.

44. Crenshaw KW. On intersectionality: essential writings: The New Press; 2017.

45. Potter LN, Lam CY, Cinciripini PM, Wetter DW. Intersectionality and smoking cessation: exploring various approaches for understanding health inequities. Nicotine Tob Res. 2021;23(1):115-23. https://doi.org/10.1093/ntr/ntaa052.

46. Windsor LC, Dunlap E. What is substance use about? Assumptions in New York's drug policies and the perceptions of African Americans who are lowincome and using drugs. J Ethn Subst Abus. 2010;9(1):64-87. https://doi. org/10.1080/15332640903539260.

47. Park S, Lee H, Min S. Factors associated with electronic cigarette use among current cigarette-smoking adolescents in the Republic of Korea. Addict Behav. 2017;69:22-6. https://doi.org/10.1016/j.addbeh.2017.01.002.

48. Cooper M, Harrell MB, Perry CL. A qualitative approach to understanding real-world electronic cigarette use: Implications for measurement and regulation. Prev Chronic Dis. 2016;13(1):1-9.

49. Fotiou A, Kanavou E, Stavrou M, Richardson C, Kokkevi A. Prevalence and correlates of electronic cigarette use among adolescents in Greece: a preliminary cross-sectional analysis of nationwide survey data. Addict Behav. 2015;51:88-92. https://doi.org/10.1016/j.addbeh.2015.07.021.

50. Dautzenberg B, Berlin I, Tanguy M-L, Rieu N, Birkui P. Factors associated with experimentation of electronic cigarettes among Parisian teenagers in 2013. Tob Induc Dis. 2015;13(1):1-6. https://doi.org/10.1186/s12971-015-0065-4

51. Durkin K, Williford DN, Turiano NA, Blank MD, Enlow PT, Murray PJ, et al. Associations between peer use, costs and benefits, self-efficacy, and adolescent E-cigarette use. J Pediatr Psychol. 2021;46(1):112-22. https://doi. org/10.1093/jpepsy/jsaa097.

52. Rocheleau GC, Vito AG, Intravia J. Peers, perceptions, and e-cigarettes: a social learning approach to explaining e-cigarette use among youth. J Drug Issues. 2020;50(4):472-89. https://doi.org/10.1177/0022042620921351.

53. Trucco EM, Cristello JV, Sutherland MT. Do parents still matter? The impact of parents and peers on adolescent electronic cigarette use. J Adolesc Health. 2021;68(4):780-6. https://doi.org/10.1016/j.jadohealth.2020.12.002.

54. Miller $P$, Plant $M$. The family, peer influences and substance use: findings from a study of UK teenagers. J Subst Abus. 2003;8(1):19-26. https://doi. org/10.1080/1465989021000067209.

55. Li S, Keogan S, Taylor K, Clancy L. Decline of adolescent smoking in Ireland 1995-2015: trend analysis and associated factors. BMJ Open. 2018;8(4): e020708. https://doi.org/10.1136/bmjopen-2017-020708.

56. Lessard J, Henrie J, Livingston JA, Leonard KE, Colder CR, Eiden RD. Correlates of ever having used electronic cigarettes among older adolescent children of alcoholic fathers nicotine \& tobacco research. 2014; 16(12):1656-60. https://doi.org/10.1093/ntr/ntu148.

\section{Publisher's Note}

Springer Nature remains neutral with regard to jurisdictional claims in published maps and institutional affiliations.
Ready to submit your research? Choose BMC and benefit from:

- fast, convenient online submission

- thorough peer review by experienced researchers in your field

- rapid publication on acceptance

- support for research data, including large and complex data types

- gold Open Access which fosters wider collaboration and increased citations

- maximum visibility for your research: over $100 \mathrm{M}$ website views per year

At BMC, research is always in progress.

Learn more biomedcentral.com/submissions 